\title{
Comparison Upper Lip Bite Test and Mallampati Test in the Prediction of Difficult Laryngoscopy
}

\author{
Amir Asadi Fakhr1,* (iD), Masoud Tarbiat ${ }^{2}$ \\ ${ }^{1}$ MSc in Anesthesiology, Department of Anesthesiology, School of Paramedicine, Hamadan University of Medical Sciences, \\ Hamadan, Iran \\ ${ }^{2}$ Associate Professor, Department of Anesthesia, School of Medicine, Hamadan University of Medical Sciences, Hamadan, \\ Iran \\ * Corresponding Author: Amir Asadi Fakhr, Department of Anesthesiology, School of Paramedicine, Hamadan University \\ of Medical Sciences, Hamadan, Iran.Email: Infotext2002@gmail.com
}

\begin{tabular}{|c|c|}
\hline & Abstract \\
\hline $\begin{array}{l}\text { Received: } 11.10 .2019 \\
\text { Accepted: } 22.01 .2020\end{array}$ & $\begin{array}{l}\text { Background and Objective: Intubation is the most common method for } \\
\text { the management of the upper airway in general anesthesia. In this regard, the }\end{array}$ \\
\hline \multirow[t]{2}{*}{$\begin{array}{l}\text { How to Cite this Article: } \\
\text { Asadi Fakhr A, Tarbiat M. } \\
\text { Comparison Upper Lip Bite Test } \\
\text { and Mallampati Test in } \\
\text { the Prediction of Difficult } \\
\text { Laryngoscopy. Avicenna J Clin } \\
\text { Med. 2020; 26(4): 241-246. } \\
\text { DOI: 10.29252/ajcm.26.4.241 }\end{array}$} & $\begin{array}{l}\text { for the anesthesia team. The main cause of anesthesia-related mortality is } \\
\text { failed airway management. The present study aimed to compare the accuracy } \\
\text { of the upper lip bite (ULBT) test and mallampati test in the fast prediction of } \\
\text { difficult intubation. } \\
\text { Materials and Methods: This descriptive-analytical study was conducted } \\
\text { on } 418 \text { patients. Prior to anesthesia, the degree of difficulty of intubation was } \\
\text { predicted using two predictive tests, namely Mallampati test and upper lip } \\
\text { bite test. In addition, after anesthesia, the degree of predicted difficulty was } \\
\text { compared with the Cormack-Lehane classification of laryngoscopic view. } \\
\text { Results: As evidenced by the obtained results, the frequency of difficult } \\
\text { intubation was reported as 5.3\%. Sensitivity, specificity, and negative } \\
\text { predictive value of ULBT test were measured at } 21.4 \%, 95.3 \% \text {, and } 97.2 \% \text {, } \\
\text { respectively. Moreover, the accuracy was obtained at } 92.8 \% \text { which was the } \\
\text { highest value. On the other hand, sensitivity, specificity, and negative } \\
\text { predictive value of Mallampati test were estimated at } 34.7 \%, 87.5 \% \text {, and } \\
91 \% \text {, respectively. In addition, the accuracy of this was reported as } 81.3 \% \text {. } \\
\text { Conclusion: The results of the current study indicated that ULBT test as an } \\
\text { easy method with high specificity, high predictive value, and high accuracy } \\
\text { in the evaluation and prediction of difficult laryngoscopy is more suitable } \\
\text { than Mallamati. }\end{array}$ \\
\hline & $\begin{array}{l}\text { Keywords: Intubation, Laryngoscopy, Mallampati Test, Upper Lip Bite } \\
\text { Test }\end{array}$ \\
\hline
\end{tabular}


dof: $10.29252 /$ ajcm.26.4.241

\section{مقايسه آزمون لب كزه و آزمون مالامياتى در يشگَويى لارنكوسكويَى مشكل}

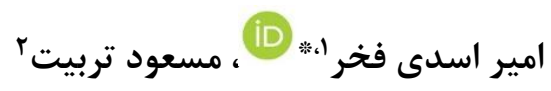

' عضو هيأت علمى، كروه هوشبرى، دانشكده بِيرايزشكى، دانشكاه علوم يزشكى همدان، همدان، ايران

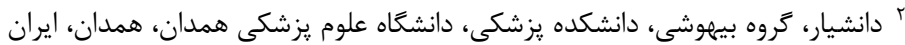

Infotext2002@gmail.com : و نويسنده مسئول: امير اسدى فخر، كروه هوشبرى، دانشكده بِيرايزشكى، دانشًاه علوم يزشكى همدان، همدان، ايران. ايميل

\begin{tabular}{|c|c|}
\hline جكيده & \\
\hline سابقه و هدف: لوله حذارى داخل تراشه، رايـجتـرين شـيوه اداره راه هـــوايى فوقــــى در بيهوشى عمومى & 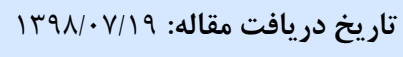 \\
\hline بوده و ييشبينى آسانى و يا دشوارى لوله َذارى براى تيم بيهوشى اهميت بسيار زيادى دارد. شكست در تعبيه & 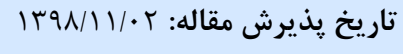 \\
\hline 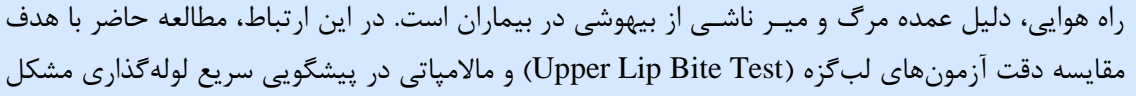 & تمامى حقوق نشر براى دانشكاه علوم \\
\hline 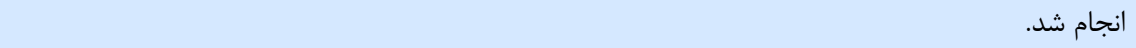 & \\
\hline 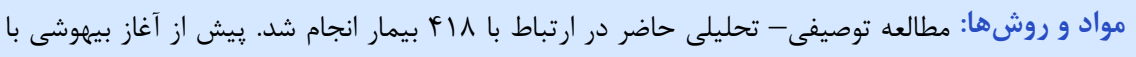 & \\
\hline 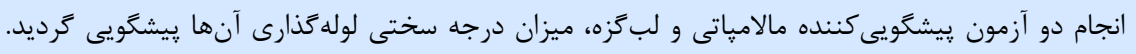 & \\
\hline يس از انجام بيهوشى نيز درجه سختى ييشكويى شده با نماى لارنكوسكويى Cormac-Lehane مقايسه شد. & \\
\hline يافته ها: نتايج نشاندهنده فراوانى لوله كذارى مشكل در س/ه درصد از افراد بودند. حساسيت، ويزگى و ارزش & \\
\hline 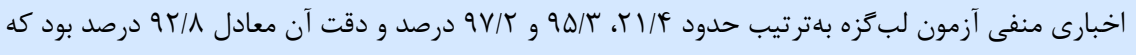 & \\
\hline بالاترين مقدار مى باشد. حساسيت، ويزّگى و ارزش اخبارى منفى آزمون مالامياتى نيز بهترتيب برابر با MF/V، & \\
\hline 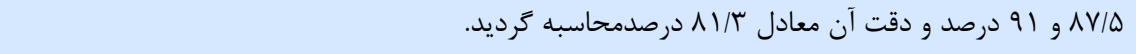 & \\
\hline نتيجهَيرى: نتايج نشان دادند كه آزمون لبكزه بهعنوان روشى آسان و داراى ويثَىى، ارزش اخبارى بالا، & \\
\hline دقت بيشتر در ارزيابى و يِيخًويى راه هوايى مشكل، روشى مناسبتر از آزمون مالامياتى مىباشد. & \\
\hline وازَّان كليدى: آزمون لبكزه،، آزمون مالامياتى، لارنغوسكويى، لولهَذارى . & \\
\hline
\end{tabular}

مقلdمه

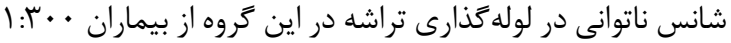

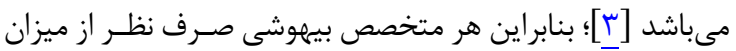

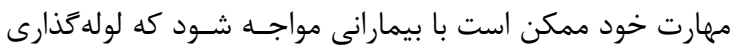

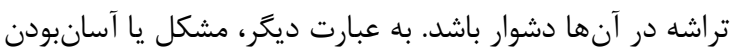

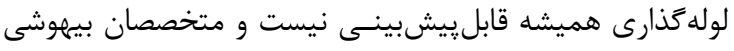

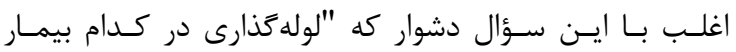

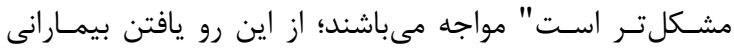

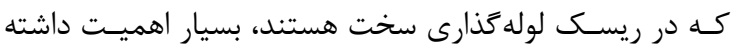

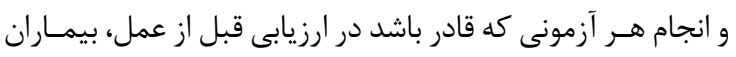

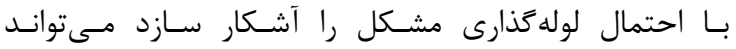
نجاتبخش جان بيماران باشد. از آنجايى كه بيشبينى جان بيمارن باندن اين مشكلات قبل از القاى بيهوشى

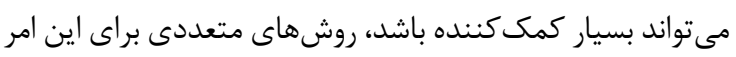

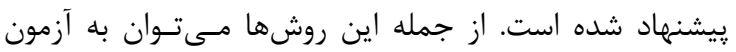

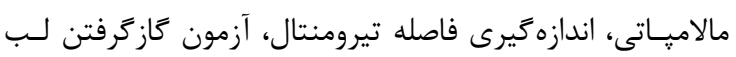

لولهَذارى داخل تراشه، رايـجتـرين شـيوه بــراى اداره راه

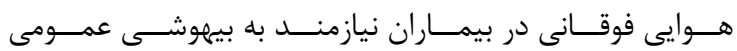

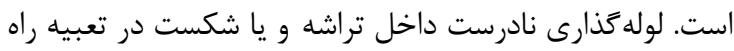
هوايى، دليل عمده مرتى و ميـر ناشسى از بيهوشى در بيماران

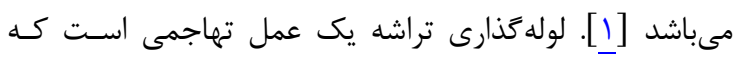

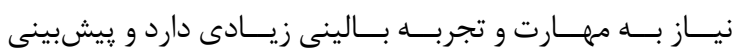

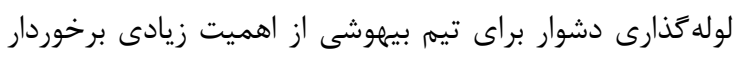

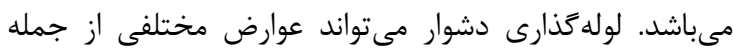
كلودرد تا آسيب جدى راه هوايى، آسيب مغزى و و حتى مرى درى بيمار

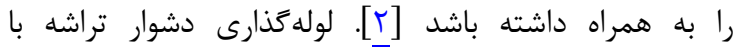

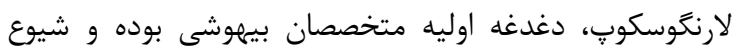

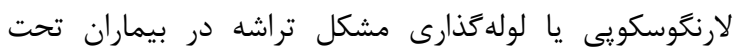

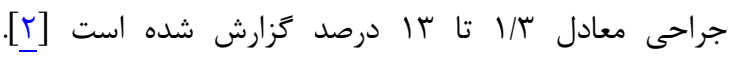
علاوهبر اين، لولهزذارى دشوار بهعنوان مهممترين عامل مرى و و مير

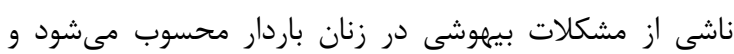


در كلاسهاى ب و f مالامياتى قرار داشتند و نيز بيمارانى كه

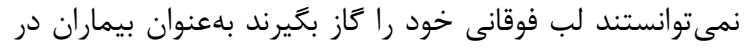

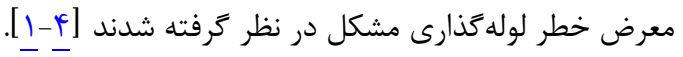

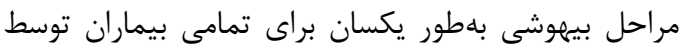

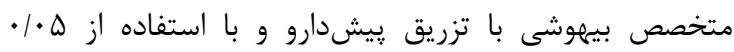

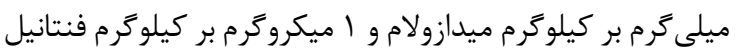

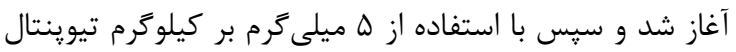

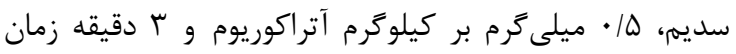

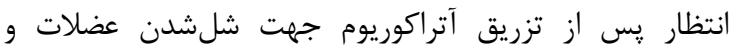

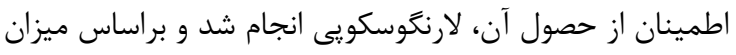

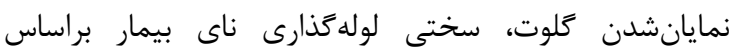
طبقهبندى Cormac-Lehane بهعنوان آزمون استاندارد مورد ارزيابى قرار زرفت. بايد خاطرنشان ساخت كه بيماران نيازمند عمل جراح

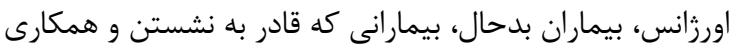

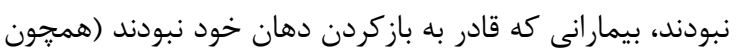

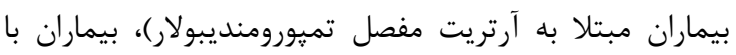

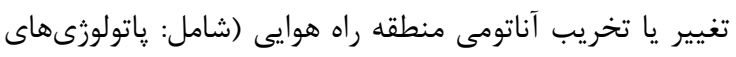

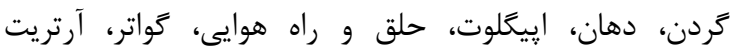

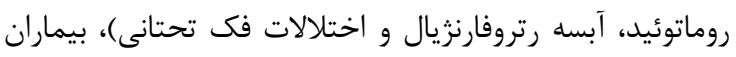

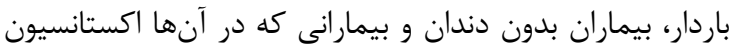
كردن جايز نبود از مطالعه كنار كذاشته شدند وندارند

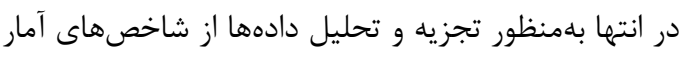
توصيفى و استنباطى در محيط نرمافزار 22 SPSS استفاده كرديد.

\section{بافته ها}

از مجموع \أ| فرد مورد بررسى در اين مطالعه، ||

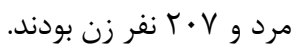

يكى از متغيرهاى اثركذار بر اين مطالعه، وضعيت زانه

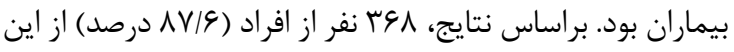

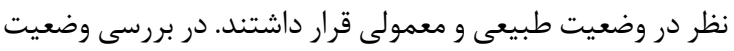

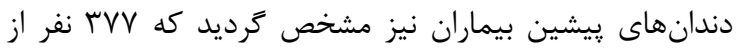

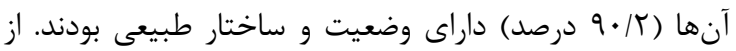

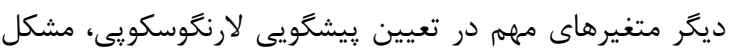

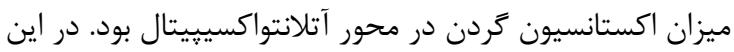

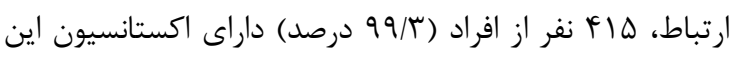

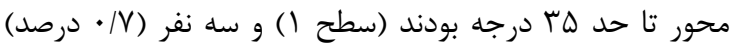

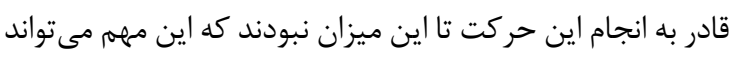

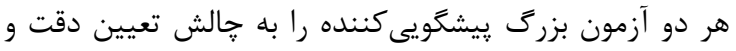

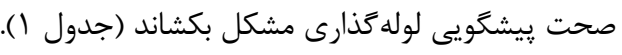

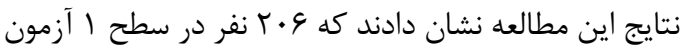

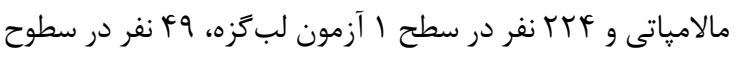

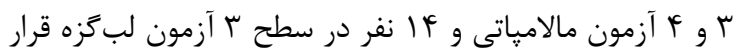

فوقـانى و فاصله دندانهـاى ثنايـا اشاره نمود [ــ-1_]. يـك آزمون

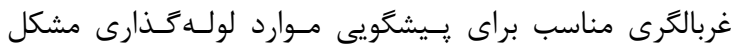

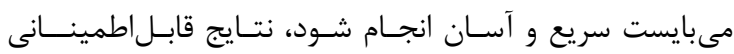

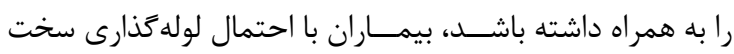
را به درستى مشخص كند (يعنى حساسيت بالايى داشـته باشـد)

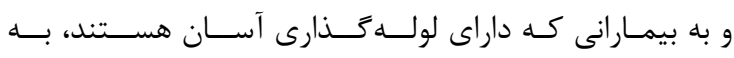

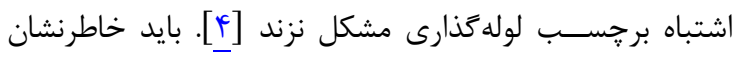

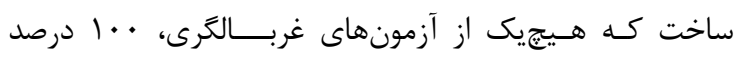

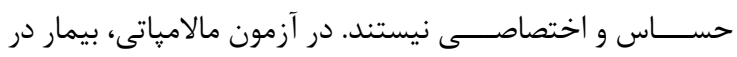

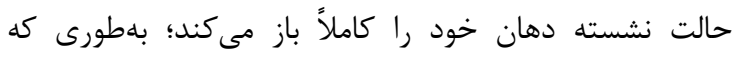

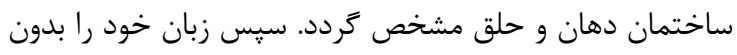

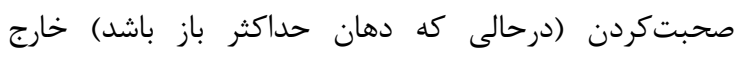

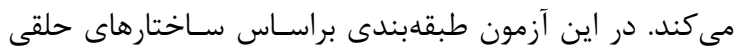

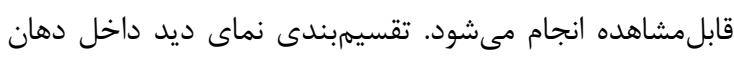

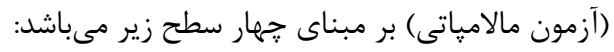

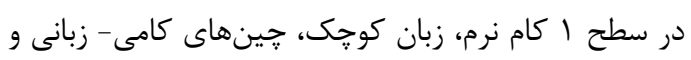
كامى - حلقى كاملاً يديدار هستند.

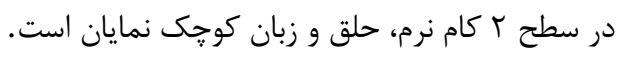

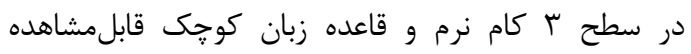
مىباشد. در سطح ץ كام نرم مشاهده نمى شود.

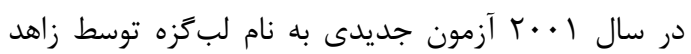
حسين خان براى ارزيابى راه هوايى ابداع ترديد. مطالعات نشان إندان

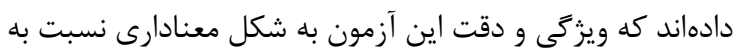

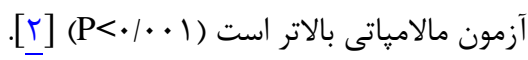

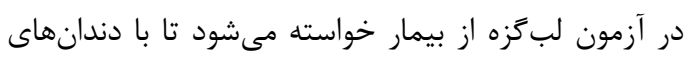

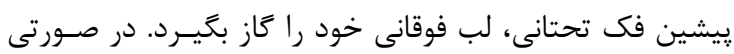

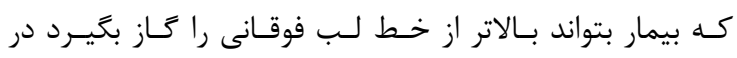

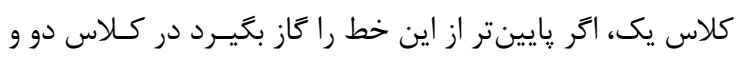

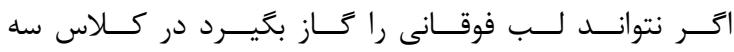

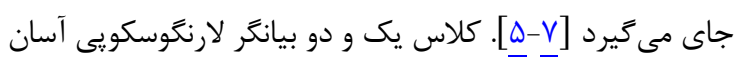

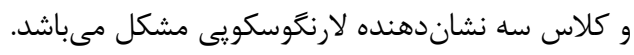

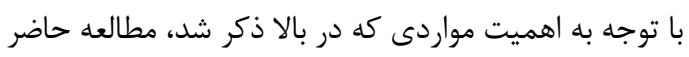

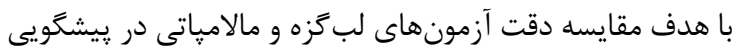
سريع لولهُذارى مشكل انجام شد.

\section{مواد و روشها}

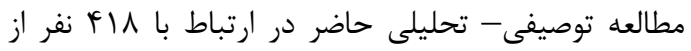

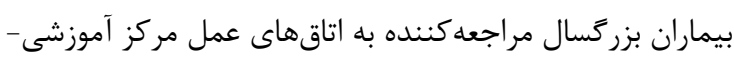

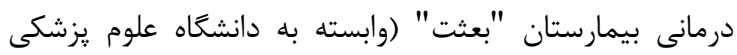

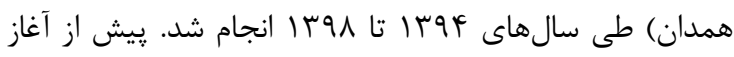

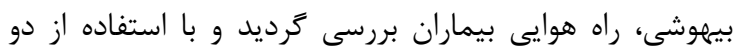

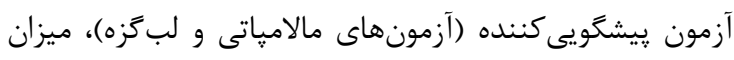

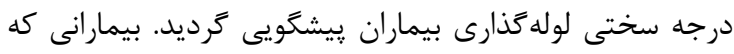


جدول ا: بررسى وضعيت آناتوميكى بيماران مورد مطالعه

\begin{tabular}{|c|c|c|c|}
\hline درصد & 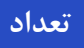 & وضعيت & \\
\hline $9 / \pi$ & rद & كوجى & \multirow{4}{*}{ جانه } \\
\hline$r / r$ & If & عقبرفته & \\
\hline$r / f$ & $1 \cdot$ & جلوآمده & \\
\hline$\Lambda N / 1$ & ra凡 & طبيعى & \\
\hline $9 \cdot / r$ & $r V V$ & طبيعى & \multirow{4}{*}{ دندانهاى يِيشين } \\
\hline$r / 9$ & 10 & جلوآمده & \\
\hline $\boldsymbol{F} / \Lambda$ & $r \cdot$ & يكى سالم و يكى افتاده & \\
\hline $1 / 4$ & 9 & هر دو افتاده & \\
\hline $99 / \Gamma$ & fid & اكستانسيون به ميزان هَّ درجه & \multirow{2}{*}{ ميزان اكستانسيون گردن در محور آتلانتواكسيييتال } \\
\hline$\cdot / V$ & r & اكستانسيون كمتر از ه广 درجه & \\
\hline
\end{tabular}

جدول ب: توزيع فراوانى وضعيت آزمونهاى مالامياتى و لبزّه در بيماران مورد مطالعه

\begin{tabular}{|c|c|c|c|}
\hline تعداد (درصد) & وضعيت آزمون لبكزه & تعداد (درصد) & وضعيت آزمون مالامياتى \\
\hline$(\Delta T / \mathcal{G})$ TYF & سطح 1 & $(\varphi q / r) r \cdot \varphi$ & سطح 1 \\
\hline$(\mathcal{F} / 1) \backslash \Lambda$. & سطح r & r (५) (צ) & سطح r \\
\hline$(T / T) \backslash f$ & سطح r & $(9 / 9) F \cdot$ & سطح r \\
\hline - $\quad-$ & $-\quad-$ & $(T / T)^{9}$ & سطح F \\
\hline$(1 \cdots) F \mid \wedge$ & 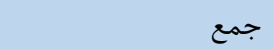 & $(1 \cdots) f \mid \wedge$ & 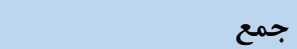 \\
\hline
\end{tabular}

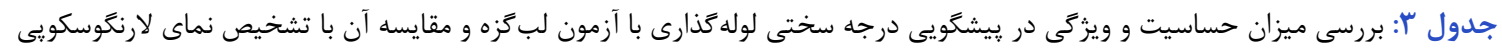
Cormac-Lehane

\begin{tabular}{|c|c|c|c|}
\hline \multirow[b]{2}{*}{ 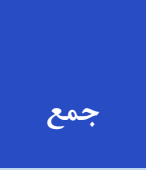 } & 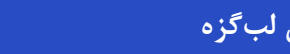 & 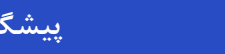 & \multirow[b]{2}{*}{ تشخيص با آزمون Cormac-Lehane } \\
\hline & 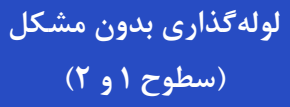 & 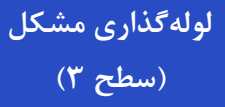 & \\
\hline $\operatorname{lf}(\omega / \Gamma)^{*}$ & $\|(\vee \wedge / 9) \mathrm{FN}$ & $r(Y, / F) \mathrm{TP}$ & لولهَذارى مشكل (سطوح َ و F) \\
\hline$F \cdot F(q F / V)$ & $\Gamma \wedge \Delta(9 \Delta / \Gamma) \mathrm{TN}$ & $19(Y / V) F P$ & لولهَذارى بدون مشكل (سطوح او r) \\
\hline$F \backslash \wedge(1 \cdots)$ & r৭\& (१F/VF) & $r T\left(\Delta / T_{G}\right)$ & 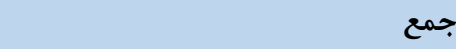 \\
\hline
\end{tabular}

: مثليه اعداد داخل : برانتز درصد مىباشند.

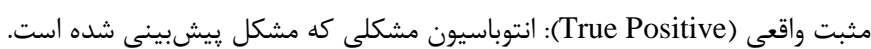

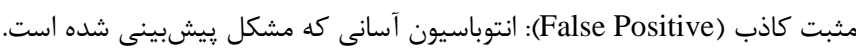

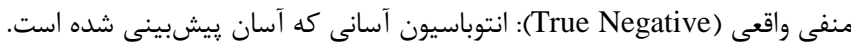

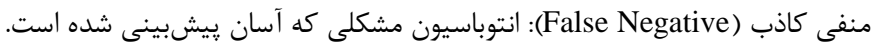

منفى) با استفاده از آزمون لبكزه داراى ارزش اخبارى منفى

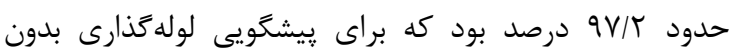
مشكل، مقدار كاملاً مناسبى مىباشد.

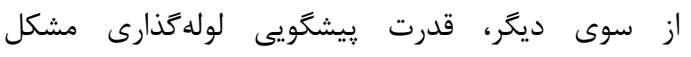

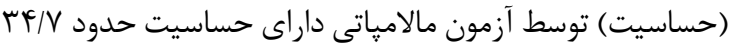

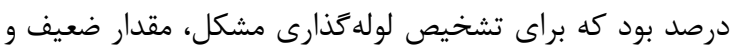

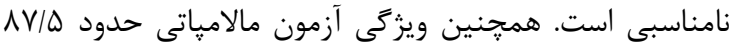

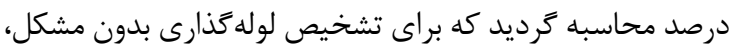

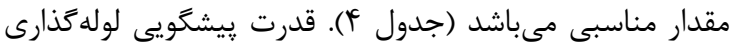

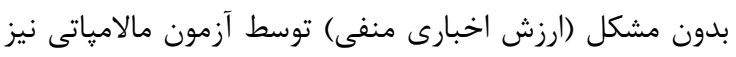

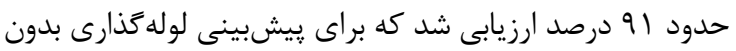

$$
\begin{aligned}
& \text { داشتند. براساس بيشگويى هر دو آزمون، اين افراد در معرض }
\end{aligned}
$$

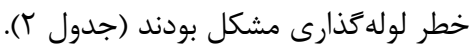

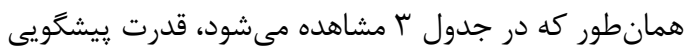

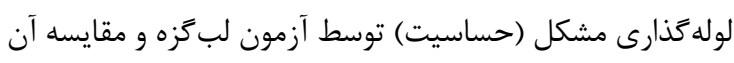


جدول Fا: بررسى ميزان حساسيت و ويزَى در بيشكَويى درجه سختى لولهَذارى با آزمون مالامياتى و مقايسه آن با تشخيص نماى لارنغوسكوبى Cormac-Lehane

\begin{tabular}{|c|c|c|c|}
\hline \multirow[b]{2}{*}{ جمع اع } & \multicolumn{2}{|c|}{ بيشكَويى با آزمون مالامياتى } & \multirow[b]{2}{*}{ Cormac-Lehane تشخيص با آزمون } \\
\hline & 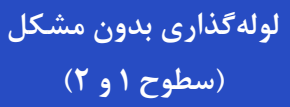 & لولهَذارى مشكل & \\
\hline$q q(10 / 1)$ & $r T(\varepsilon \Delta / r) \mathrm{FN}$ & IV (TF/V) TP & لولهَذارى مشكل (سطوح r و F F) \\
\hline rGq (^F/q) & 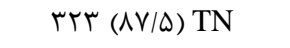 & $F \varphi(I Y / \Delta) \mathrm{FP}$ & لوله كذارى بدون مشكل (سطوح او r) \\
\hline$f \backslash \wedge(1 \cdots)$ & $r \Delta \Delta(\Lambda F / q r)$ & $g r(\mid \Delta / \cdot \Lambda)$ & 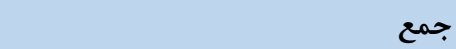 \\
\hline
\end{tabular}

مطابقت دارد. بايد خاطرنشان ساخت كه دقت آزمون لبكزه (Accuracy)

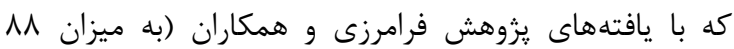
درصد) همسو مىباشد [1]

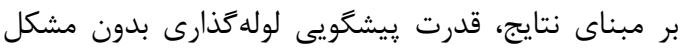

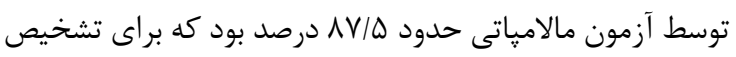

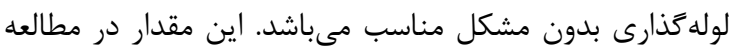

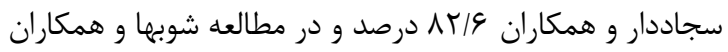

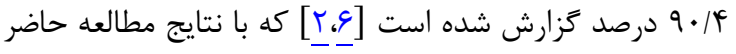
مطابقت دارد. قدرت بيشكويى لولهَذارى مشكل توسط آزمون

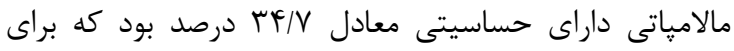

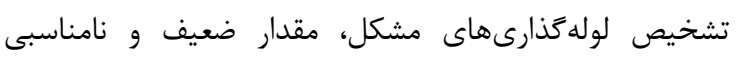

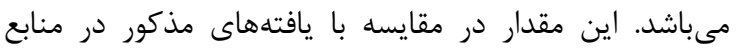

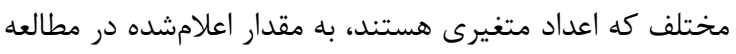

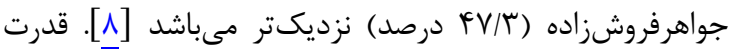

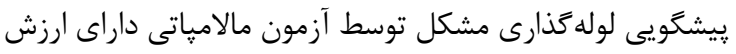

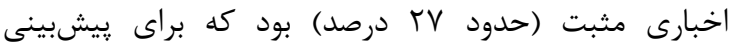
لوله حذارى مشكل، ضعيف مى باشد. اين مقدار در مطالعه سجاددار

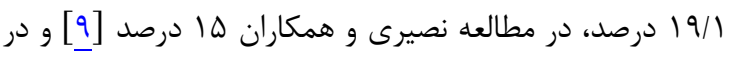

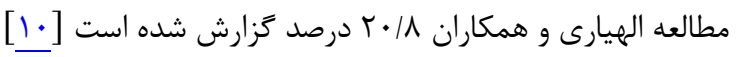

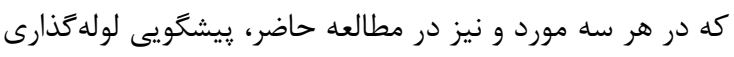

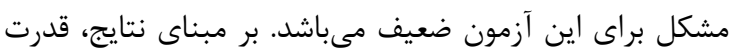

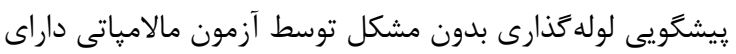

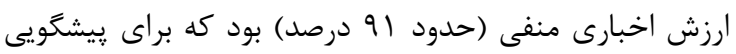

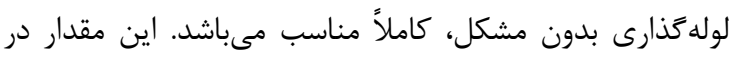

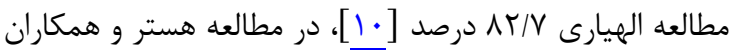

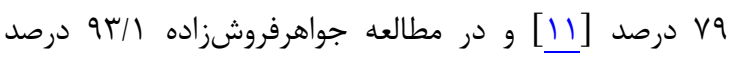
گزارش گرديده است [^] كه با يافتههاى مطالعه حاضر كاملاً

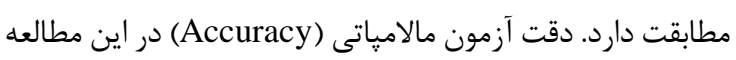

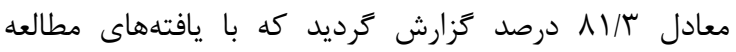
سجاددار ( 1 درصد) كاملاً همسويى دارد.

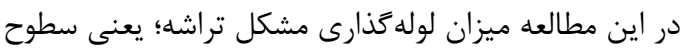

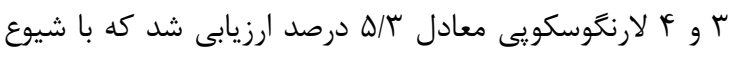

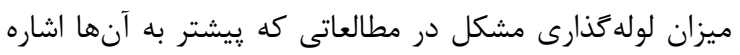

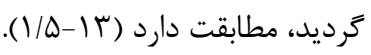

مشكل، مقدار كاملاً مناسبى است.

امروزه ارزيابى راه هوايى بهمنظور كشف لارنكوسكويىهاى

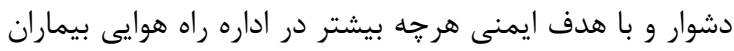

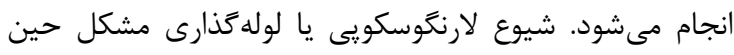

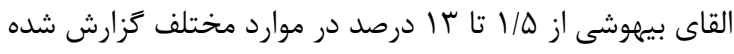

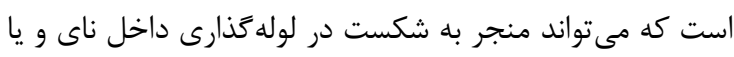

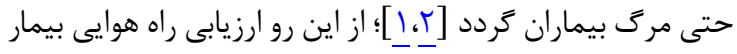

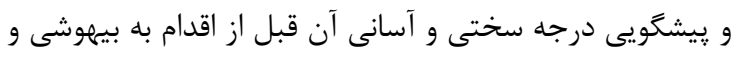

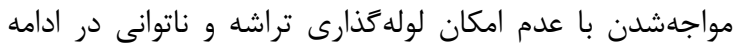

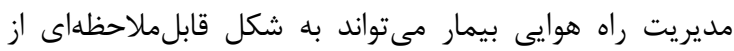
دشوارى و مشكلات بعدى آن بكاهد.

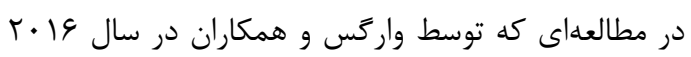

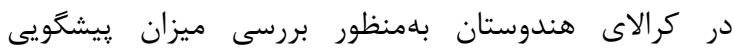

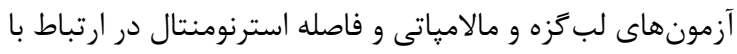

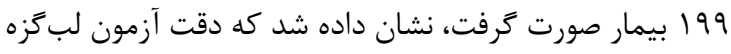

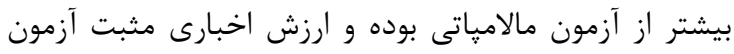

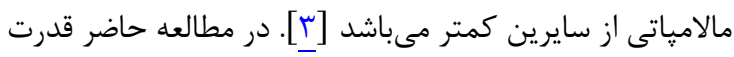

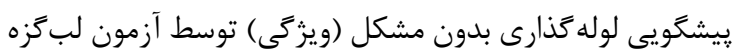

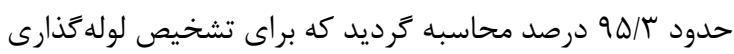

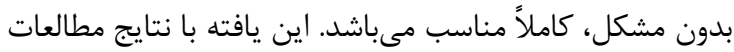

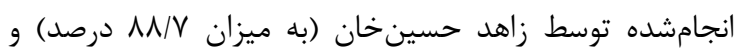

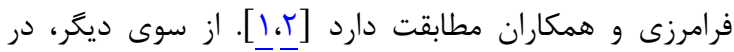

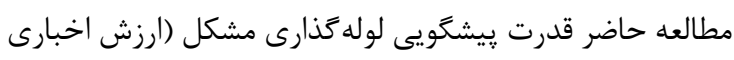

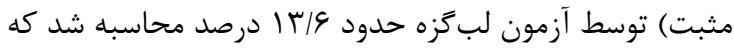

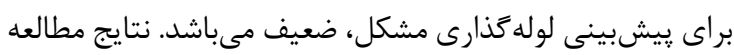

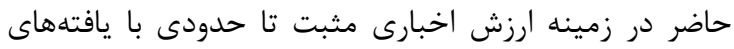

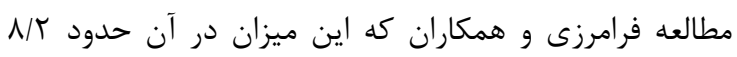

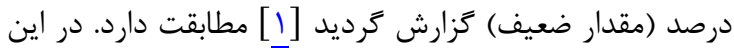

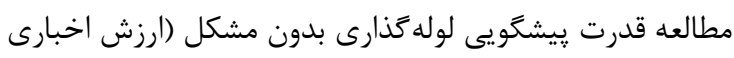

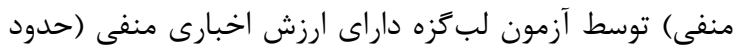

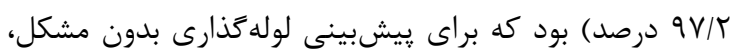

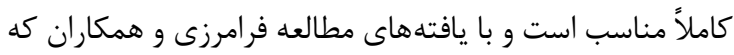

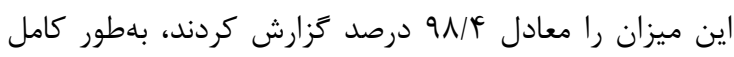




$$
\begin{aligned}
& \text { بيهوشى و كاركنان اتاق عمل بيمارستان فوق تخصصى بعثت }
\end{aligned}
$$

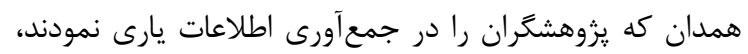

$$
\begin{aligned}
& \text { تشكر و قدردانى مى }
\end{aligned}
$$

تضاد منافع

بين نتايج مطالعه و منافع نويسندكان هيجز كونه تضاد منافعى

$$
\text { كزارش نشده است. }
$$

\section{ملا حظات اخلاقى}

$$
\begin{aligned}
& \text { اين مطالعه داراى نامه تأييديه از كميته اخلاق دانشعاه علوم }
\end{aligned}
$$

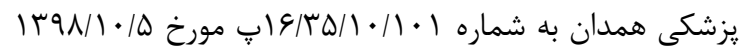

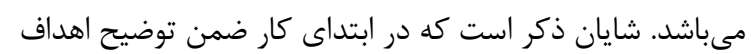

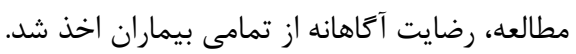

\section{سمهم ذويسنلمكان}

نويسنده اول (يزوهشخر اصلى): طراحى يروزثه، نوشتن

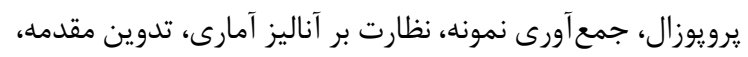

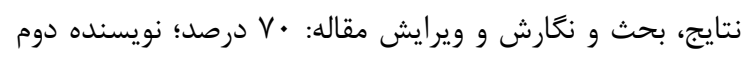

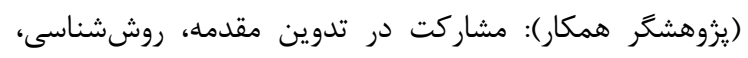

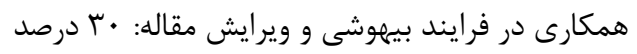

\section{حمايت مالَى}

هزينه انجام طرح توسط معاونت تحقيقات و فناورى دانشعاه

$$
\text { علوم يزشكى همدان تأمين شده است. }
$$

\section{REFERENCES}

1. Faramarzi E, Soleimanpour H, Khan ZH, Mahmoodpoor A, Sanaie S. Upper lip bite test for prediction of difficult airway: a systematic review. Pak J Med Sci. 2018;34(4):1019-23. PMID: 30190773 DOI: 10.12669/pjms.344.15364

2. Dar SA, Khan MS, Iqbal FA, Nazeer T, Hussain R. Comparison of upper lip bite test (ULBT) with mallampati classification, regarding assessment of difficult intubation. Pak J Med Health Sci. 2017;11:767-9.

3. Varghese A, Mohamed T. A comparison of Mallampati scoring, upper lip bite test and sternomental distance in predicting difficult intubation. Int J Res Med Sci. 2016; 4(7):2645-8. DOI: 10.18203/2320-6012.ijrms20161925

4. Zahedi H, OstadAlipour A, Jamshidi M, Nikoseresht M, Malaki A, Noori M. Evaluation of upper lip bite test (ULBT) for prediction of difficult intubations. Iran J Anesthesiol Crit Care. 2016;38(94):51-60. [Persian]

5. Hirmanpour A, Safavi M, Honarmand A, Jabalameli M, Banisadr G. The predictive value of the ratio of neck circumference to thyromental distance in comparison with four predictive tests for difficult laryngoscopy in obstetric patients scheduled for caesarean delivery. Adv Biomed Res. 2014;3:200. PMID: 25337530 DOI: 10.4103/22779175.142045

6. Shobha D, Adiga M, Rani DD, Kannan S, Nethra SS. Comparison of upper lip bite test and ratio of height to thyromental distance with other airway assessment tests
بررسىهاى صورت گرفته در مطالعه حاضر حاكى از آن بودند

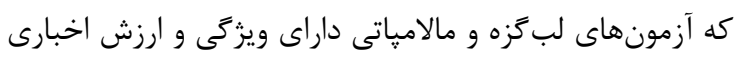

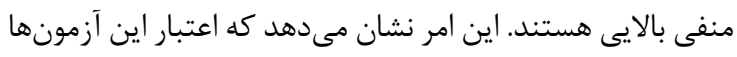

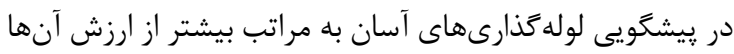

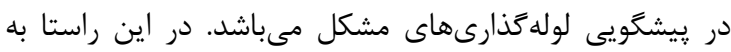

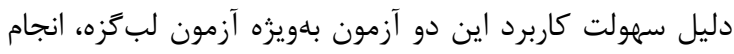

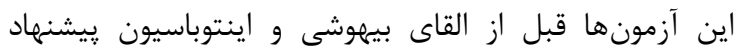

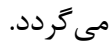

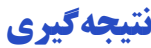

با توجه به مسائل و عواقب لوله كذارىهاى مشكل، اين

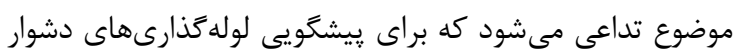

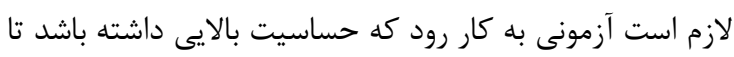

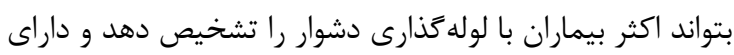

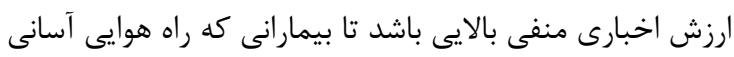

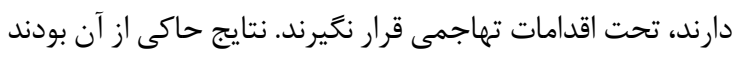

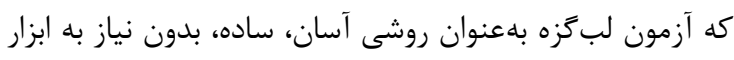

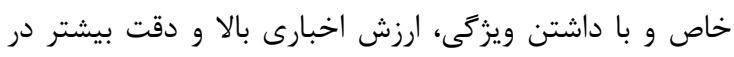

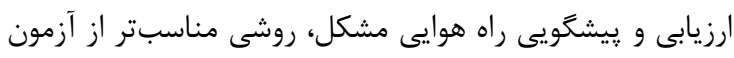
مالامياتى مىباشد.

\section{تشكر و قلرواذى}

اين مقاله بركرفته از طرح تحقيقاتى مصوب دانشخاه علوم

يزشكى همدان مىباشد. بدينوسيله از متخصصان و كارشناسان

for predicting difficult endotracheal intubation. Anesth Essays Res. 2018;12(1):124-9. PMID: 29628567 DOI: 10.4103/aer.AER_195_17

7. Roth D, Pace NL, Lee A, Hovhannisyan K, Warenits AM, Arrich J, et al. Bedside tests for predicting difficult airways: an abridged cochrane diagnostic test accuracy systematic review. Anaesthesia. 2019;74(7):915-28. PMID: 30843190 DOI: 10.1111/ANAE.14608

8. Javaherforooshzadeh F, Pipelzadeh M, Goosheh M, Safaii S. Determination of the sensitivity and specificity of airway evaluation tests (Malampaty, ULBT, Thyromental distance, Inter incisors gap) in predicting difficult tracheal intubation. J Iranian Soc Anaesthesiol Intens Care. 2012;34(2):59-64. [Persian]

9. Nasiri E, Akbari H, Farrokhi H, Ebrahimi F, Nasiri R. A comparison of the upper lip bite test with inter incisor distance in predicting difficult laryngoscopy and tracheal intubation. J Mazandran Univ Med Sci. 2013;23(105):71-9. [Persian]

10. Allahyary E, Ghaemei SR, Azemati S. Comparison of six methods for predicting difficult intubation in obstetric patients. Iran Red Cresent Med J. 2008;10(3):197-201.

11. Hester CE, Dietrich SA, White SW, Secrest JA, Lindgren KR, Smith T. A comparsion of preoperative air way assessment techniques: the modified Mallampati and Upper lip Bite Test. AANA J. 2007;75(3):177-82. 